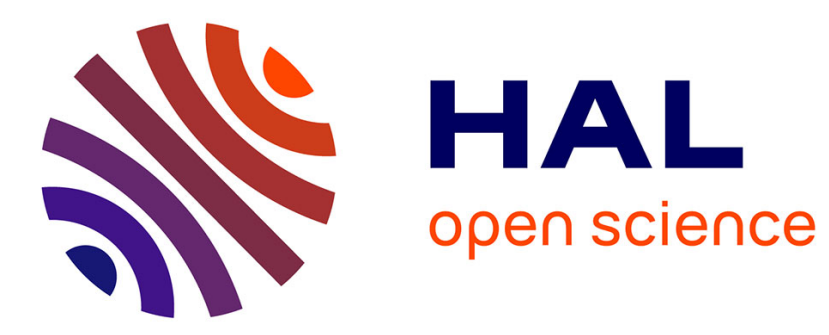

\title{
EVIDENCE FOR COARSE STRUCTURE (INTERMEDIATE RANGE ORDER) IN METAL-AMMONIA SOLUTIONS
}

\author{
P. Chieux
}

\section{- To cite this version:}

P. Chieux. EVIDENCE FOR COARSE STRUCTURE (INTERMEDIATE RANGE ORDER) IN METAL-AMMONIA SOLUTIONS. Journal de Physique IV Proceedings, 1991, 01 (C5), pp.C5-373C5-375. 10.1051/jp4:1991545 . jpa-00250672

\section{HAL Id: jpa-00250672 https://hal.science/jpa-00250672}

Submitted on 1 Jan 1991

HAL is a multi-disciplinary open access archive for the deposit and dissemination of scientific research documents, whether they are published or not. The documents may come from teaching and research institutions in France or abroad, or from public or private research centers.
L'archive ouverte pluridisciplinaire HAL, est destinée au dépôt et à la diffusion de documents scientifiques de niveau recherche, publiés ou non, émanant des établissements d'enseignement et de recherche français ou étrangers, des laboratoires publics ou privés. 


\title{
EVIDENCE FOR COARSE STRUCTURE (INTERMEDIATE RANGE ORDER) IN METAL AMMONIA SOLUTIONS
}

\author{
P. CHIEUX
}

Institut Laue-Langevin, 156X, F-38042 Grenoble cedex, France

The detailed analysis of concentration fluctuations near critical point $\left(\mathrm{x}_{\mathrm{c}}=\right.$ critical mole fraction, $T_{c}$ ) for liquid-liquid immiscibility in sodium-ammonia solutions has confirmed the existence ( at $\left(T-T_{c}\right)=1.5 \pm 0.5 \mathrm{~K}$ ) of a sharp crossover from critical to mean field regime $/ 1 /$. This crossover occurs for correlation lengths $60<\xi(A)<100$ as observed for $T>T_{c}$ and $x=x_{c}$, but probably at values $30<\xi(\AA)<50$ for $T<T_{c}$, along the two branches of the coexistence curve. We should therefore address ourselves to the following question. Is there any such characteristic observable length of the system which could be associated with the critical to mean field transition? Let us briefly revisit past experimental structural investigations, in the light of this question.

Several trials $/ 2 / \sqrt{ } / 3 /$ have been made to apply the Ginzburg criterion for defining the respective range of validity of the critical and mean field regime in Metal-Ammonia. The first attempt to obtain the characteristic correlation length of the system gave a value $\xi_{o}=5 \AA$, significantly larger than the value $\xi_{\mathrm{o}}=1.6 \AA$ obtained in $\mathrm{K}-\mathrm{KBr}$ solutions ( where critical regime is obeyed, up to $\left(\mathrm{T}-\mathrm{T}_{\mathrm{c}}\right)=30 \mathrm{~K}$ at least $)$. However recent accurate measurements in the critical regime give $\xi_{0}=2.98 \AA$ for $\mathrm{Na}-\mathrm{ND}_{3} / 4 /$, a value close to the molecular size, which is too small to be quantitatively correlated to the observed location of the crossover.

In order to obtain characteristic distances of the system greater than atomic or molecular sizes, one must look for so-called prepeaks or superstructure peaks in the structure factor. Indeed at very high metal concentration as from $n=4$ to 6 in $\mathrm{Li}_{\mathrm{nND}}$ ( 20 to $14 \%$ metal content ), the total structure factor measured by neutron scattering displays a prepeak $/ 4 /$. The position of this prepeak shifts from $1 \AA^{-1}$ ( for $n=4$ ) to $0.945 \AA^{-1}(n=6)$, and its position which is a linear function of the cube root of concentration, corresponds to a real space distance of about $7 \AA$, related to the spacing of solvated ion units.

How does the prepeak behave while diluting the sample to reach critical concentration? This question has not been directly investigated by neutron scattering, but useful information has nevertheless been obtained. The linear dependence of the prepeak position with respect to the cube root of concentration seems to break down for $\mathrm{Li}_{\mathrm{nND}}$ concentrations between $\mathrm{n}=6$ and 7 ( where the peak shifts significantly from 0.945 to $0.75 \pm 0.04 \AA^{-1}$ ), with a stepwise increase of the solvated ion spacing from 7 to $9 \AA$. At critical concentration $x_{c}=0.04$, an anomaly in the 
Ornstein-Zernike description of critical scattering has been detected at $q=0.26 \pm 0.07 \AA^{-1}$, which is qualitatively attributed to the solvated ion distribution.

Interestingly, old small angle X-Ray scattering measurements by P.W. Schmidt /5/ on $\mathrm{Li}-\mathrm{NH}_{3}$ solutions corroborate the neutron scattering results for $\mathrm{x}=20 \%$ and detect peaks at $0.77 \pm 0.04$ and $0.22 \pm 0.03 \AA^{-1}$ for the respective mole fractions $x=10.6 \%$ and $1.77 \%$, on both sides of the coexistence curve. Closer to critical concentrations at $x=7.05$ and $3.62 \%$, a shoulder at respectively $0.62 \pm 0.08$ and $0.35 \pm 0.06 \AA^{-1}$ is seen at the foot of the strong small angle signal due to critical fluctuations, but some doubts remain on these findings as the experiment was quoted at more than 10 degrees below $\mathrm{T}_{c}$ without mentioning phase separation !

At Colloque Weyl IV, Knapp and Bale /6/, reported a series of small angle X-Ray measurements on both $\mathrm{Li}$ and $\mathrm{Na}$-ammonia solutions at various concentrations (typically $1,2,3,4,6,10,16 \%$ ) and temperatures above and below critical. They confirmed the findings of Schmidt and observed at concentrations near $x_{c}$ a shoulder at $0.4 \pm 0.05 \AA^{-1}$ on the tail of the critical scattering. Moreover, their results indicate that the position of this shoulder (varying from 0.3 to $0.42 \mathrm{~A}^{-1}$ ) depends linearly on mole fraction in the range $1<x<4.3 \%$.
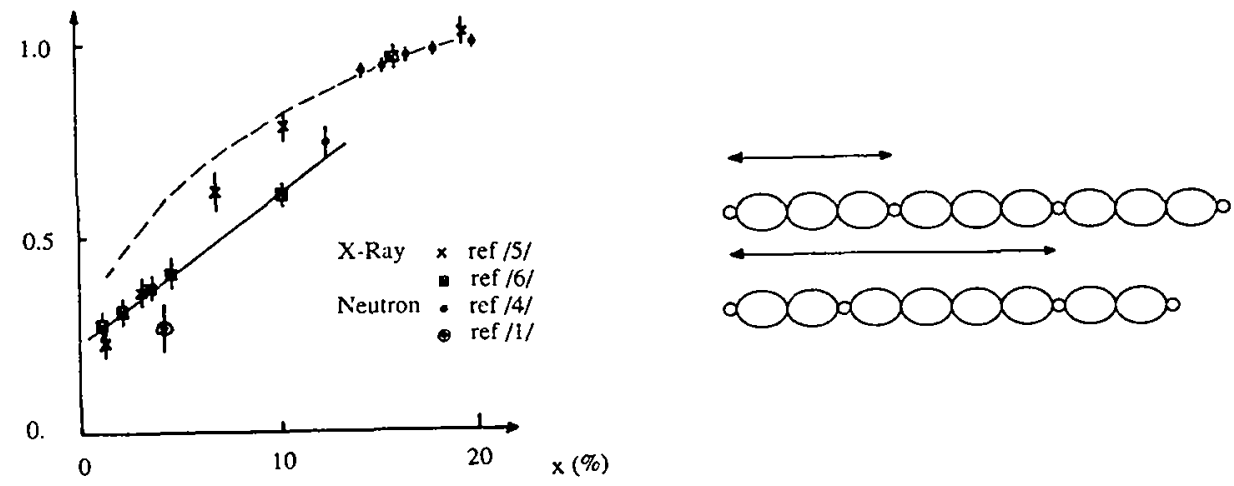

Figure 1. Linear ( - ) or cube root ( - - ) dependence of the prepeak position versus $\mathrm{Li} \mathrm{nND}_{3}$ concentration.

Figure 2. One-dimensional representation of the coarse structure.

The available information on the prepeak position is summarized in figure 1 , lines corresponding to the cube root or to the linear dependence on concentration are drawn. There is an apparent uncertainty on the concentration at which departure from the cube root behavior occurs, and on the sharpness of this departure, but at near critical concentration, the peak position is at $0.35 \pm 0.08 \AA^{-1}$ i-e well below the cubic root behavior. In other words, a characteristic structure of periodicity $20<\mathrm{r}(\AA)<30$ is observable near the critical point in $\mathrm{Li}-\mathrm{NH}_{3}$ solutions and this structure is not due to a random spatial distribution of solvated ions in the solvent (which should have an average interionic distance of $12 \AA$ ). Some aggregation occurs for which a simple 
one-dimensional picture is given in Figure 2. At concentration near to $4 \%$, there are on average 3 ammonia molecules separating the $\mathrm{Li}$ ions, which gives a $\mathrm{Li}$ - $\mathrm{Li}$ distance of about $12 \AA$. By displacing one ammonia molecule, we obtain alternatively 2 and 4 ammonia molecules between the $\mathrm{Li}$ ions, which creates a new structure with a $24 \AA$ periodicity. This simple description has several implications. It applies well when the average number of ammonia molecules separating the $\mathrm{Li}$ ions is comprised between 4 and 2 , $\mathrm{i}$-e for mole fractions in the range $1.6<\mathrm{x}(\%)<11$ (we note that it roughly corresponds to the limits of the miscibility gap). It does not introduce large aggregates of solvated ions but only a local segregation favoring near neighbor contacts, which in three dimensions could lead to a network of solvated ions, as in a percolation model . It also gives a microscopic support to the thermodynamic description of the free energy (which considers the system as a regular solution of $\mathrm{NH}_{3}$ and solvated ions $/ 7 /$ ).

We have limited our description to Li-ammonia solutions where solvation effects are strong and a stable compound exists, but small angle $X$-Ray results $/ 6 /$ indicate that a similar description could be given for $\mathrm{Na}$-ammonia solutions, with a shorter periodicity of the coarse structure near critical concentration $(-15 \AA)$, but we should be aware of the severe experimental difficulties.

In conclusion, a coarse structure is observed in Metal-Ammonia solutions at concentrations in the vicinity of the liquid-liquid immiscibility. Its size is of the order of the characteristic length at which the crossover between critical and mean field regime occurs. A simple model explains it by the nano-segregation of a solvated ion network. The prevailing concept describing Metal-Ammonia solutions as an homogeneous system developing concentration fluctuations at the approach to the critical point, should be modified in favor of a locally heterogeneous system ( at the scale of $20 \AA$ ) developing concentration fluctuations, with a clear distinction between fluctuations with a correlation length greater or smaller than the coarse structure size. We should pursue the study of the stability of the coarse structure with respect to temperature and better define the concentration range in which a random distribution of the solvated ions is not observed. Finally, the bimodal model description of the transport properties /8/, should be reviewed in the light of the above remarks.

\section{References}

/1/ P.Chieux, J-F. Jal, L. Hily, J. Dupuy, F. Leclercq, P. Damay, these proceedings

/2/ M.J. Sienko in "Metal-Ammonia Solutions" Colloque Weyl I, Ed. G. Lepoutre and M.J. Sienko, W.A. Benjamin, N-Y, 23-40 (1964)

13/ P. Chieux, P. Damay, J. Dupuy, J-F. Jal, J. Phys. Chem $\underline{84}$, 1211-1215 (1980)

14/ P. Chieux, H. Bertagnolli, J. Phys. Chem. $\underline{88}$, 3726-3730 (1984)

15/ P.W. Schmidt, J. Chem. Phys. 27 (1) 23-28 (1957)

/6/ D.N. Knapp, H.D. Bale, Colloque Weyl IV, (1975), J. Appl. Cryst.11, 606 (1978)

7/ P. Damay, P. Schettler, J. Phys. Chem 79 , 2930 (1975)

18/ M.H. Cohen, J. Jortner, J. Phys. Chem 79 (26), 2900-2915 (1975) 